\title{
The American Democracy Project 2014 Annual Meeting
}

The combined American Democracy Project / Democracy Commitment annual meeting in Louisville, KY.

\section{Abstract}

In 2014, the eJournal of Public Affairs produced this documentary to reveal some of the rationale realized by its partnership with the American Democracy Project, ADP. Viewed historically, the video captures a moment in time when the ADP started to expand its vital partnerships, as expressed in the issue's Intro Essay Editorial. As a reference for how much the ADP has evolved in a short period of time, these shared testimonials from earlier attendees convey the message and intent of focused partnership that has always been the core of the conference. In this time of challenging issues for the practice of our democracy, the eJournal encourages the growth of collaboration, discussion, and action as engaged citizens.

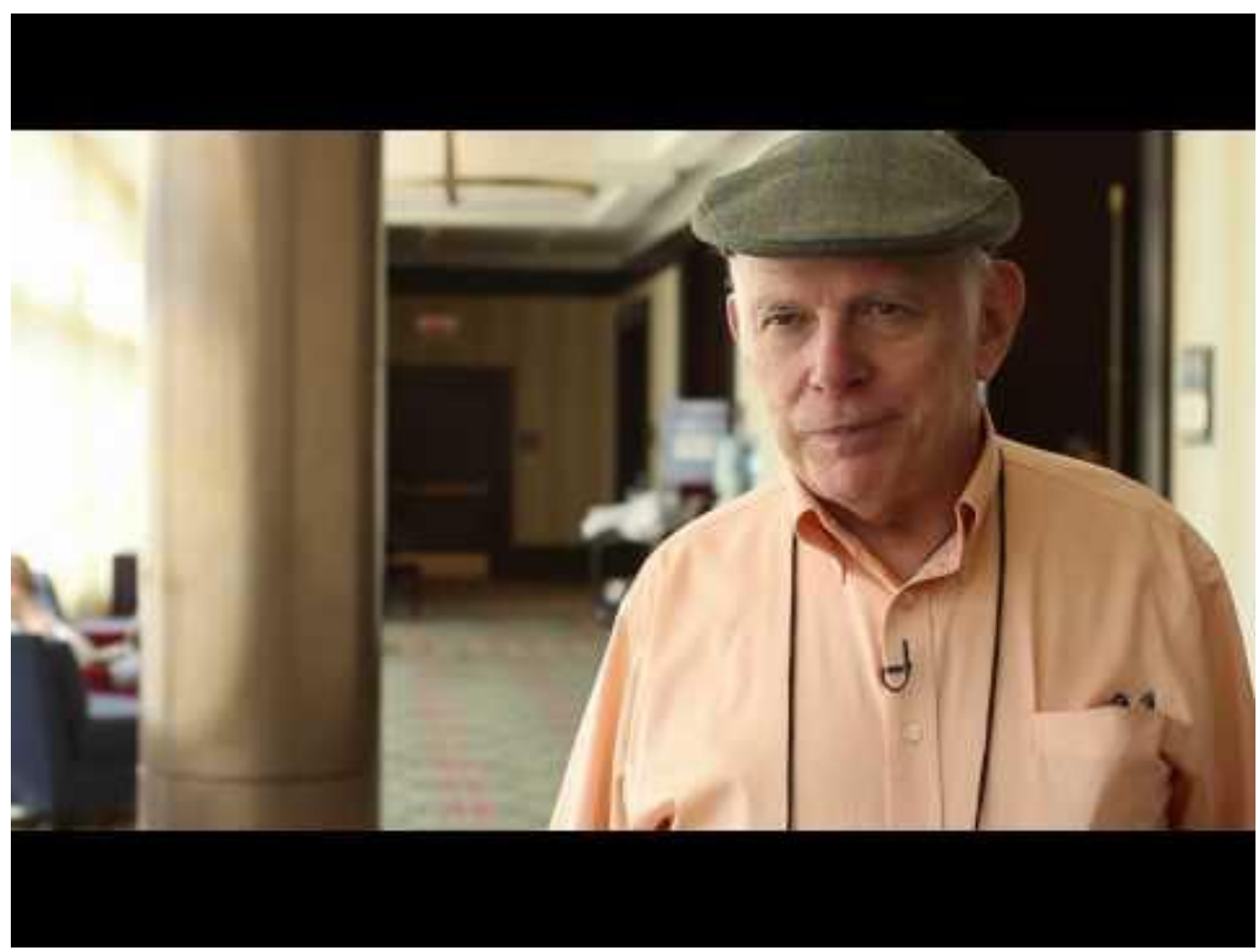

https://www.youtube.com/watch?v=LmILiBBXHK4\&feature=youtu.be 

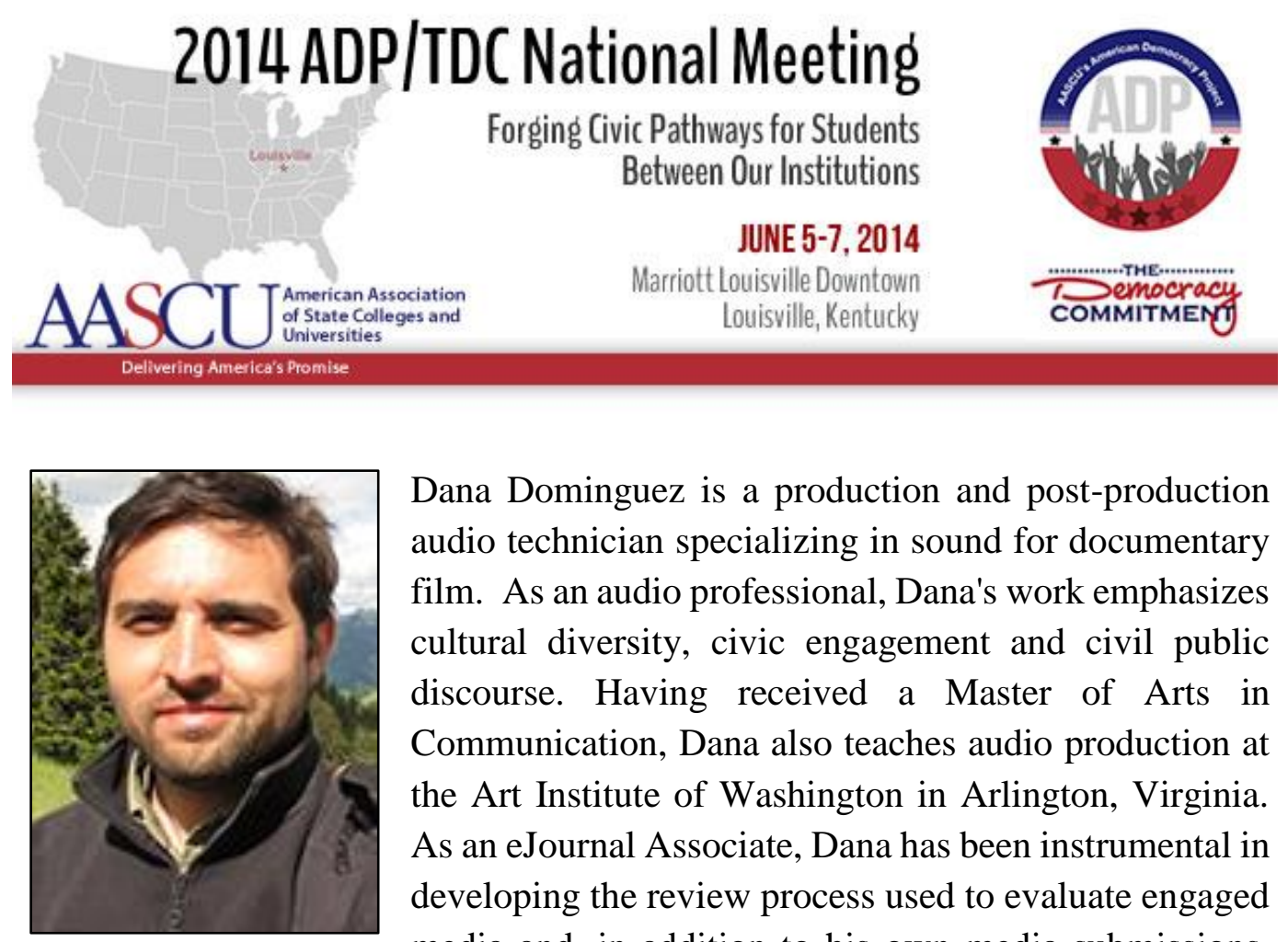

Dana Dominguez is a production and post-production audio technician specializing in sound for documentary film. As an audio professional, Dana's work emphasizes cultural diversity, civic engagement and civil public discourse. Having received a Master of Arts in Communication, Dana also teaches audio production at the Art Institute of Washington in Arlington, Virginia. As an eJournal Associate, Dana has been instrumental in developing the review process used to evaluate engaged media and, in addition to his own media submissions, also participates in new developments as the eJournal evolves its multi-media format. 